\title{
Teenage Pregnancies: Obstetric Outcomes and their Socio Economic Determinants a Descriptive Study at Teaching Hospital Kandy
}

Ekanayake C D ${ }^{1}$, Tennakoon S U B ${ }^{2}$, Hemapriya $S^{1}$

\section{Abstract}

Introduction: Teenage pregnancies account for approximately $6.1 \%$ of total pregnancies in Sri Lanka. The objectives of the study were to assess obstetric and psychological outcomes and socioeconomic determinants of teenage pregnancy.

Method: A cross-sectional descriptive study carried out on 182 pregnant teenagers for a period of seven months. The validated translation of the Edinburgh Postnatal Depression Scale (EPDS), questions on socioeconomic status and obstetric outcomes were recorded.

Results: Teenage pregnancy rates for Singhalese, Tamil and Muslim were $87.4 \%, 8.2 \%$ and $4.4 \%$ respectively. The social support was adequate as $177(97 \%)$ were living with partners or parents. Unwanted pregnancies accounted for $13(7.1 \%)$ of teenage pregnancies at term. Outcomes were; birth weight $2.69 \mathrm{~kg}(2.57-2.81 \mathrm{~kg})$, pre-term labour $17(9.7 \%)$, hypertensive disorders $20(11.1 \%)$ and perinatal depression $30(16.5 \%) .75(42.9 \%)$ of pregnant teenagers were separated from one or both parents for more than six months in their childhood. There were no pregnant teenagers from upper social class, while 69(46.6\%) were from middle and $79(53.4 \%)$ were from lower social class. Disruption to family structure and parental educational level of primary school less had 2.32 times and 2.78 times higher risk of perinatal depression in pregnant teenagers respectively.

Conclusion: Teenage pregnancies in Sri Lanka are unique compared to other countries as they did not appear to be related to ethnicity and had good social support. Disruption to family structure and socioeconomic background of the parents were risk factors for adolescent pregnancy. Although the majority were wanted pregnancies there was a significant amount of unwanted pregnancies at term.

Keywords: Teenage pregnancy, adolescent pregnancy, obstetric outcomes, Kuppuswamy socio-economic scale, perinatal depression

\section{INTRODUCTION}

Although the incidence of teenage pregnancy is declining in most western countries, the scenario in developing countries may be changing for the worse $^{1}$. The family health bureau of Sri Lanka estimates teenage pregnancies to be approximately $6.1 \%$ of total pregnancies ${ }^{2}$.

Studies done in Europe show that the most consistent factor associated with teenage pregnancy is a low socioeconomic status including disruption

\footnotetext{
${ }^{1}$ Teaching Hospital Kandy, Sri Lanka

${ }^{2}$ Department of Community Medicine, University of Peradeniya, Sri Lanka

Correspondence: Dr. CD Ekanayake

E-mail: cdekanayake2000@yahoo.co.uk

Competing interests: None
}

of family ${ }^{3,4}$. This factor could be a potential risk factor in Sri Lanka, as breakdown of family structure is a frequent event due to mothers leaving the country to work as domestic aides or fathers joining the defence forces. A dislike of attending school also appears to be associated with an increased risk of teenage pregnancy ${ }^{5}$. The educational status of parents may also be an independent risk factor which has however not been assessed.

Pregnancy induced hypertension, preeclampsia, preterm labour, low birth weight and increased neonatal morbidity and mortality have been found to be associated with teenage pregnancies $6,7,8,9$.

Psychiatric disorders are also found to be more prevalent in pregnant teenagers with $32.5 \%$ having at least one psychiatric disorder while one third had two or more psychiatric disorders ${ }^{10}$. Postnatal depression was the commonest psychiatric disorder, albeit with a wide variation in the prevalence due to different methods used. However postnatal depression is now accepted to be around $13 \%{ }^{11}$. The adverse psychological effects of teenage pregnancy may be of greater concern than obstetric or medical complications as it may limit education, employment and lifelong career opportunity for teenage mothers ${ }^{12}$. This may itself cause mental trauma that would have consequences for subsequent children [13]. However it is not known if depression occurrs independently of socio-economic factors in teenage pregnancies. Although India and Sri Lanka have high adolescent pregnancy rates it is noteworthy to consider the fact that the rural sector accounts for the majority of teenage pregnancies in Sri Lanka ${ }^{2,14}$. Traditionally pregnant mothers from rural sector have a supportive family background which may probably explain the relatively better obstetric outcome of teenage pregnancies in Sri Lanka ${ }^{15}$. There were no studies assessing the outcome of teenage pregnancy independent of socio-economic risk factors in Sri Lanka. This study was carried out to determine the prevalence of selected socioeconomic risk factors, obstetric outcome and perinatal depression in pregnant teenagers delivering in ward 06 of the Teaching hospital, Kandy.

\section{METHODS}

A cross-sectional descriptive study was done from December 2009 to June 2010 including all teenage mothers (13-19 years) delivering in ward 06, Teaching Hospital, Kandy, Sri Lanka. Assuming a 13\% prevalence of postnatal depression [11], with a margin of error of $5 \%$ and a power of $80 \%$, a minimum sample size of 
174 was calculated. Eligible patients were briefed on the study by the principal investigator and informed written consent was obtained. Data was collected using a questionnaire on day one after delivery. Assistance was given by ward staff only for patients who were unable to complete the questionnaire on their own. Information related to obstetric outcome of the pregnancy were recorded by the principal investigator after reviewing medical records of the patients.

Hypertensive disorders in Pregnancy was diagnosed based on the International Society for the Study of Hypertension in Pregnancy (ISSHP) classification ${ }^{16}$. Vaginal, instrumental, caesarean section were considered as the modes of delivery. Low birth weight was considered as a birth weight less than $2.5 \mathrm{~kg}$. Pre-term birth was taken as delivery of a baby $<37$ weeks completed pregnancy. Edinburgh Postnatal Depression Scale
(EPDS) which is an accepted screening tool for 'perinatal depression' was used on day one after delivery ${ }^{17}$. The validated Sinhala and Tamil translations of the EPDS were used for this purpose and a score of nine or more was considered as screening test positive for perinatal depression ${ }^{18,19}$.

Disruption to family structure was considered in 3 categories; those who lived with both parents, those who lived with only one parent for more than 6 months or those who did not live with any parent for more than 6 months in their childhood. The educational status of both the mother and father were obtained, and whichever that was higher was considered as the educational level of the parents. The educational level of subjects were also obtained. Categorization of the educational status was based on the updated 'Kuppuswamy' socioeconomic scale [Table 01$]^{20}$. The occupational status of parents, partner and patient were obtained. Categorization of the occupation was also based on the updated 'Kuppuswamy' socioeconomic scale [Table 01] ${ }^{20}$. The parental occupational status was the higher level of occupation in either the mother or father. The categorization of monthly income was also based on the updated 'Kuppuswamy' socioeconomic scale $^{20}$. It was adjusted for a Sri Lankan scenario by multiplying the income categories by the Purchasing Power Parity (PPP) ratio between Sri Lanka and India at the time of the study [Table 01] ${ }^{21}$. Categorization into socioeconomic class was based on parental parameters; combined parental income, occupation and level of education using the 'Kuppuswamy' socioeconomic class scale [Table I] ${ }^{20}$. Ethical approval was obtained from the Ethical Review Committee of the Faculty of Medicine, Peradeniya, Sri Lanka.

Table I - Kuppuswamy socioeconomic class scale as applied to Sri Lanka

\begin{tabular}{|c|c|c|c|c|c|}
\hline \multirow[t]{2}{*}{ Educational status } & \multirow[b]{2}{*}{ Score } & \multicolumn{2}{|l|}{ Occupation } & \multicolumn{2}{|l|}{ Monthly income } \\
\hline & & & Score & Rupees * & Score \\
\hline Illiterate & 1 & Unemployed & 1 & $<2506 /=$ & 1 \\
\hline$\geq$ Primary-middle $\dagger$ & 2 & Unskilled & 2 & $2506-7515 /=$ & 2 \\
\hline$\geq$ Middle -pre secondary $\ddagger$ & 3 & Semi-skilled & 3 & $>7515-12526 /=$ & 3 \\
\hline Pre secondary & 4 & Skilled & 4 & $>12526-18744 /=$ & 4 \\
\hline Secondary & 5 & Technical & 5 & $>18744-25055 /=$ & 6 \\
\hline Post-graduate & 6 & Semi-professional & 6 & $>25055-50109$ & 10 \\
\hline Honours & 7 & Professional & 10 & $>50109$ & 12 \\
\hline
\end{tabular}

*The income categories in India were multiplied by the ratio of PPP difference between India and Sri Lanka. The PPP for India was 2.16 while it was 5.53 for Sri Lanka at the time of the study. Therefore the income categories for Sri Lanka were 2.56 times the Indian income categories. The above mentioned values were for Sri Lanka.

†Represents primary school up to middle school

$\ddagger$ Represents middle school up to pre secondary

Interpretation of Socioeconomic classes by score; 26-29 upper, 16-25 upper middle, 11-15 lower middle, 5-10 upper lower and $<5$ lower class respectively. 
Table II - The basic characteristics of subjects $(n=182)$

\begin{tabular}{lll}
\hline Age & $\mathrm{n}$ & Percentage $\%$ \\
\hline$<17$ years & 15 & $8.2 \%$ \\
$\geq 17$ years & 167 & $91.8 \%$ \\
Mean age & 18.1 & \\
Range & $(15-19)$ & \\
$95 \%$ Cl & $(18-18.2)$ & \\
\hline Ethnicity & & \\
Sinhalese & 159 & $87.4 \%$ \\
Tamil & 15 & $8.2 \%$ \\
Muslim & 8 & $4.4 \%$ \\
\hline Background & & \\
Living with partner & 93 & $51.1 \%$ \\
Living with parents & 84 & $46.2 \%$ \\
Living alone & 5 & $2.7 \%$ \\
\hline Pregnancy & & \\
Planned & 73 & $40.2 \%$ \\
Unplanned but wanted & $96.3 \%$ \\
Unwanted & 13 & $52.7 \%$ \\
\hline Educational status of patient & 16 & $7.1 \%$ \\
Illiterate & & \\
$>$ Primary - middle school & & \\
$>$ Middle school - secondary & & \\
\hline
\end{tabular}

Table III - Obstetric outcomes

\begin{tabular}{llll}
\hline & $\mathrm{n}$ & Percentage \% & $(95 \% \mathrm{Cl})$ \\
\hline $\begin{array}{l}\text { Mode of delivery } \\
\text { Vaginal }\end{array}$ & 124 & $68.1 \%$ & $(63.5-72.7 \%)$ \\
$\begin{array}{l}\text { Instrumental } \\
\text { Caesarean section }\end{array}$ & 12 & $6.6 \%$ & $(2.9-10.3 \%)$ \\
\hline Birth weight * & 46 & $25.3 \%$ & $(19-31.6 \%)$ \\
Mean (kg) & & & \\
$<2.5 \mathrm{~kg}$ & & & $2.69(2.57-2.81)$ \\
\hline Pre-term labour ** & 46 & $25.8 \%$ & $(5.3-14.1 \%)$ \\
\hline Hypertension in pregnancy *** & 17 & $9.7 \%$ & \\
None & 159 & $88.8 \%$ & $(84.2-93.4 \%)$ \\
Hypertension only & 18 & $10.1 \%$ & $(5.7-14.5 \%)$ \\
Pre-eclampsia + eclampsia & 2 & $1.1 \%$ & $(-0.4-2.6 \%)$ \\
\hline
\end{tabular}

\footnotetext{
* Birth weight was available in 178 cases

** data regarding pre-term labour was in available in 175 cases

*** data regarding hypertension in pregnancy was available in 179 cases
}

\section{RESULTS}

A total of 182 pregnant teenagers were included in the study. Patients in the sample ranged from 15 to 19 years. The mean age was 18.1 years (18.018.2). Majority $(87.4 \%)$ of the sample were Sinhalese by ethnicity. 97\% were either living with their partner or parents. Planned pregnancies accounted for $40.2 \%$ while $52.7 \%$ were unplanned but wanted pregnancies. There were no subjects who studied beyond secondary school (Table 01).

There were 30 patients $(16.5 \%)$ who tested positive for peri-partum depression. The birth weight was 2.69 $\mathrm{kg}$ (2.57-2.81). Pre-term labour and hypertensive disorders were found in $17(9.7 \%)$ and $20(11.2 \%)$ of patients respectively (Table III).

On consideration of disruption to family structure, 5 patients did not live with their biological parents while another 70 lived with only one parent for more than 6 months during their childhood (Table IV).

Educational status was regrouped in to two main groups; less than middle school and middle school or more. (Table IV). Occupational status of parents was regrouped in to two main groups; unemployed and unskilled in one group and the other being semiskilled or more (Table IV). Parental monthly income was regrouped in to 2 main groups; less than Rs.7515 and more than Rs.7515 (Table IV). Categorization in to socioeconomic classes showed that 79 belonged to the lower class while 69 belonged to the lower middle class. There were none in the upper middle or upper classes (Table IV).

Teenage mothers who had been separated from one or both parents for more than 6 months in at some point in their childhood appeared to have a 2.32 times higher risk of having perinatal depression compared to other teenage mothers who were not separated from their parents (Table V). Patients of parents who were educated up to primary school or less had a 2.78 times higher risk of perinatal depression compared to patients whose parents were educated up to or above middle school level. The occupational status, total monthly income, socioeconomic 
class of parents, educational status of the patient, pregnancy status and birth weight of the baby was not associated with perinatal depression (Table V).
The immediate background of the patient had a bearing on the perinatal depression as three out of five patients who were living alone were screening test positive. Patients who lived with parents or partners did not have a higher risk of perinatal depression (Table V).

Table IV - Socioeconomic risk factors

\begin{tabular}{llll}
\hline & $n$ & Percentage $\%$ & $(95 \% \mathrm{Cl})$ \\
\hline $\begin{array}{l}\text { Family structure * } \\
\text { Lived with 0 or 1 parent }\end{array}$ & 75 & & $(35.6-50.2 \%)$ \\
Lived with both parents & 100 & $57.9 \%$ & $(49.8-64.4 \%)$ \\
\hline Educational status of parents ** & & & $(23.7-37.7 \%)$ \\
$<$ Middle school & 51 & $30.7 \%$ & $(62.3-76.3 \%)$ \\
$\geq$ Middle school & 115 & $69.3 \%$ & $(46.0-61.6 \%)$ \\
\hline Occupation of parents *** & & & $(38.4-54.0 \%)$ \\
Unemployed or unskilled & 85 & $53.8 \%$ & \\
Semi skilled or more & 73 & $46.2 \%$ & $(34.6-50.0 \%)$ \\
\hline Monthly income of parents **** & & & $(50.0-65.4 \%)$ \\
$<7515$ & 66 & $42.3 \%$ & \\
$>7515$ & 90 & $57.7 \%$ & - \\
\hline Socioeconomic class ***** & & & $(38.6-54.6 \%)$ \\
Upper & - & $46.6 \%$ & $(45.4-61.4 \%)$ \\
Middle & 69 & $53.4 \%$ & \\
Lower & 79 & & \\
\hline
\end{tabular}

*data available for 175 cases

**data available for 166 cases, illiterate-10, up to primary school-41, up to middle school-111, up to secondary school-4.

***data available for 158 cases, unemployed-13, unskilled job -72, semi-skilled job -29, skilled / technical grade job -44 .

****data available for 156 cases, < Rs.2506 in 10, Rs.2506 - 7515 in 56, Rs.7515 - 12526 in 41, Rs.12526 - 18744 in 27 , Rs. $18744-25054$ in 22.

$* * * * *$ data available for 148 cases 
Table V - Perinatal depression and risk factors

\begin{tabular}{|c|c|c|c|}
\hline & $\mathrm{n}(\%)$ & Odds ratio $(95 \% \mathrm{Cl})$ & $P$ value \\
\hline $\begin{array}{l}\text { Family structure } \\
\text { Lived with both parents* } \\
\text { Lived with } 0 \text { or } 1 \text { parent }\end{array}$ & $\begin{array}{l}100(57.1) \\
75(42.9)\end{array}$ & $\begin{array}{l}1 \\
2.32(0.97-5.58)\end{array}$ & 0.01 \\
\hline $\begin{array}{l}\text { Educational status of parents } \\
\geq \text { Middle school }^{*} \\
\leq \text { Primary school }\end{array}$ & $\begin{array}{l}115(69.3) \\
51(30.7)\end{array}$ & $\begin{array}{l}1 \\
2.78(1.15-6.74)\end{array}$ & 0.01 \\
\hline $\begin{array}{l}\text { Occupation of parents } \\
\text { Semi skilled or more* } \\
\text { Unemployed or unskilled }\end{array}$ & $\begin{array}{l}73(46.2) \\
85(53.8)\end{array}$ & $\begin{array}{l}1 \\
0.92(0.36-2.34)\end{array}$ & 0.84 \\
\hline $\begin{array}{l}\text { Monthly income of parents } \\
\geq \text { Rs 7515/=* } \\
<\text { Rs } 7515 /=\end{array}$ & $\begin{array}{l}90(57.7) \\
66(42.3)\end{array}$ & $\begin{array}{l}1 \\
1.25(0.52-2.98)\end{array}$ & 0.59 \\
\hline $\begin{array}{l}\text { Socioeconomic class of parents } \\
\text { Middle* } \\
\text { Lower }\end{array}$ & $\begin{array}{l}69(46.6) \\
79(53.4)\end{array}$ & $\begin{array}{l}1 \\
0.52(0.22-1.23)\end{array}$ & 0.102 \\
\hline $\begin{array}{l}\text { Educational status of patient } \\
\geq \text { Middle school }^{*} \\
<\text { Primary school }\end{array}$ & $\begin{array}{l}128(70.3) \\
54(29.7)\end{array}$ & $\begin{array}{l}1 \\
1.3(0.55-3.05)\end{array}$ & 0.51 \\
\hline $\begin{array}{l}\text { Background of patient } \\
\text { Living with parents } \\
\text { Living with partner } \\
\text { Living alone }{ }^{\star \star}\end{array}$ & $\begin{array}{l}84(46.2) \\
93(51.1) \\
05(2.7)\end{array}$ & $\begin{array}{l}1 \\
0.92(0.41-2.05) \\
\#\end{array}$ & $\begin{array}{l}0.82 \\
0.22\end{array}$ \\
\hline $\begin{array}{l}\text { Pregnancy status } \\
\text { Planned* } \\
\text { Unplanned or unwanted }\end{array}$ & $\begin{array}{l}73(40.1) \\
96(52.7)\end{array}$ & $\begin{array}{l}1 \\
0.99(0.44-2.24)\end{array}$ & 0.98 \\
\hline $\begin{array}{l}\text { Low birth weight of baby } \\
>2.5 \mathrm{~kg}^{*} \\
\leq 2.5 \mathrm{~kg}\end{array}$ & $\begin{array}{l}132(74.2) \\
27(25.8)\end{array}$ & $\begin{array}{l}1 \\
1.22(0.45-2.35)\end{array}$ & 0.92 \\
\hline
\end{tabular}

*reference category

**Fisher exact test result was taken. 


\section{DISCUSSION}

Teenage pregnancy proportions by ethnicity in the study were lower than the ethnic proportions in the community unlike in the US where a higher rate was observed among minority black and Hispanic communities $^{22,23}$. This may suggest that ethnicity may not be a risk factor for teenage pregnancy in Sri Lanka.

It is possible to assume that a majority of the study sample had a satisfactory support structure as they were living with their partner or parents, a finding that transcends ethnic, socioeconomic barriers in an Asiatic culture. However the reason for living with parents instead of their partners was not assessed and neither was it assessed whether the subject was satisfied in either of the backgrounds.

In this study almost sixty percent of the pregnancies were either unplanned or unwanted, which was comparable to a similar study done in Galle, Sri Lanka, however both studies were hospital based studies ${ }^{24}$. Of the teenagers who were delivering $7 \%$ were unwanted pregnancies even at this juncture. Whether this group of patients represents the true amount of unwanted pregnancies is doubtful as some patients may have opted for termination even if it is illegal in the present day legal backdrop.

Caesarean section rate was higher compared to other studies done in Sri Lanka which may be due to a change in obstetric practice as data in these studies were almost fifteen years old 15,25 . The setting also may be a factor as tertiary hospitals were found to have a higher rate of caesarean section compared to provincial hospitals ${ }^{25}$.

The general improvement in living standards may explain the improved rate of low birth weight in our study 15,26 . The rate of hypertension in pregnancy was very much higher than available figures from Sri Lanka ${ }^{15}$.

Disruption to family was shown to be associated with adolescent pregnancy, a trend that was observed in our study as well ${ }^{4}$. This may seem plausible in the context of a deprived socioeconomic background necessitating parents to seek employment in the security forces or work abroad as housemaids.
The immediate background of the patient; i.e. whether they were living with their parents or their partner did not appear to have a bearing on perinatal depression unless they were alone, in which case there was a high risk of perinatal depression.

Disruption to family structure during childhood was shown to be associated with a tendency for depression, which may be due to the predisposition of risk factors for depression itself such as poverty and abuse. Subgroup analysis of risk factors showed that if the parents of a teenage mother were educated up to primary school or less she would be at a higher risk of depression. However the occupation of parents and the combined parental monthly income were not associated with a risk of depression. This may be due to disparities of income and occupation that may not necessarily mirror the educational level or the presence of a supportive network for the patients which may have countered the negative effects of poverty ${ }^{27}$. An unplanned pregnancy or a low birth weight baby was not associated with depression, a fact that may further substantiate the possibility of a good supportive network in these patients in spite of their poverty.

As information of parents regarding occupation, educational level and parental income were obtained through patients there would have been some degree of inaccuracy as it was not always possible to verify the information through parents themselves as they were not always present. Another limitation was that emotional stresses may have affected the EPDS score as it was administered on day one. However the EPDS test is a screening test for perinatal depression and its true value lies in its predictive value. Furthermore if it was administered at a later date following discharge the dropout rates would have been much higher as these patients are not from 'ideal' backgrounds.

\section{CONCLUSION}

Socioeconomic factors leading to adolescent pregnancy are quite different compared to other countries as they were not prevalent in ethnic minorities and appeared to have adequate social support. Disruption to family structure and socioeconomic background of the parents were risk factors for teenage pregnancy. There was a significant amount of unwanted pregnancies even at term, a fact that suggests that the true magnitude of the problem may be far worse when taking in to account the likelihood of abortion, albeit illegal in Sri Lanka.

\section{REFERENCES}

1. Singh S, Darroch JE. Adolescent pregnancy and childbearing: levels and trends in developed countries. Family Planning Perspectives 2000; 32(1):14-23.

2. Family Health Bureau. National Statistics. Available from http://fhb.health.gov.lk/ web/index.php?option=com

3. Mari Imamura, Tucker J. Factors associated with teenage pregnancy in the European Union countries: a systematic review. Eur J Public Health 2007 17(6):630-636.

4. Vikat A, Rimpelä A, Kosunen E, Rimpelä $M$. Sociodemographic differences in the occurrence of teenage pregnancies in Finland in 1987-1998: a follow up study. $\mathrm{J}$ Epidemiol Community Health 2002; 56:659-668.

5. Bonell C, Allen E, Strange V, et al. The effect of dislike of school on risk of teenage pregnancy: testing of hypothesis using longitudinal data from a randomized trial of sex education. J Epidemiol Community Health 2005; 59:223-230.

6. Fraser AM, Brokert JE, Ward RH. Association of young maternal age with adverse reproductive outcomes. N Engl J Med 1995; 332:1113-1117.

7. Scholl TO, Hediger ML, Belsky DH. Prenatal care and maternal health during adolescent: a review and meta-analysis. J Adolesc Health 1994; 15:444-456.

8. Kumar A, Singh $T$ et al. Outcome of teenage pregnancy. Indian $\mathrm{J}$ Pediatr 2007; 74(10):927-931.

9. Olausson PO, Cnattingius S, Haglund B. Teenage pregnancies and risk of late fetal death and infant mortality. BJOG 1999;106:116-121.

10. Mitsuhiro SS, Chalem E, Moraes Barros MC, Guinsburg R, Laranjeira R. Brief report: Prevalence of psychiatric disorders in pregnant teenagers. J Adolesc. 2009;32(3):747-752. 
11. Wisner KL, Parry BL, Piontek CM. Postpartum depression. N Engl J Med 2002; 347:194-199.

12. Goonewardene M. The adolescent girl. Ceylon Med J. 2002 47(4): 111-114.

13. Horgan RP, Kenny LC. Management of teenage pregnancy. TOG 2007;9:153 158.

14. Mahavarkar SH, Madhu CK, Mule VD. A comparative study of teenage pregnancy. J Obstet Gynaecol 2008;28(6):604-7. doi: 10.1080/01443610802281831.

15. Weerasekera D. Adolescent pregnancies - is the outcome different? Ceylon Med J; 1997; 42, 16-17.

16. Davey DA, MacGillivray I. The classification and definition of the hypertensive disorders of pregnancy. Am J Obstet Gynecol 1988; 158:892-898.

17. Cox JL, Holden JM, Sagovsky R. Detection of postnatal depression: development of the 10-item Edinburgh Postnatal Depression Scale. $\mathrm{Br} \mathrm{J}$ Psychiatry 1987; 150:782-786.
18. Rowel D, Jayawardena P. Validation of the Sinhala translation of the Edinburgh postnatal depression scale. Ceylon Med J 2008;53(1): 10-13.

19. Benjamin D, Chandramohan A etal. Validation of the Tamil version of Edinburgh Post-partum depression scale. J Obstet Gynaecol India 2005; (55(3):241-243.

20. Kumar N, Shekhar P. Kuppuswamy's socioeconomic status scale-updating for 2007. Indian J Pediatr 2007; 74(12):11311132.

21. Asian Development Bank. 2005 International comparison program in Asia and the pacific. Purchasing power parities and real expenditure. Manila: Asian development bank, 2007; 40.

22. Department of Census and Statistics Sri Lanka. Brief analysis of population and housing characteristics. p 10. Available from URL: http://www.statistics.gov.lk/ PopHouSat/PDF/p7\%20population\%20 and\%20Housing\%20Text-11-12-06.pdf (Accessed on 1st July 2011)
23. Centers for Disease Control and Prevention (CDC). National and statespecific pregnancy rates among adolescents: United States, 1995-1997. MMWR Morbidity and Mortality Weekly Report 2000; 49:605-611.

24. Gunaratna K, Goonewardene $M$. Teenage pregnancy and contraception. Sri Lanka Journal of Obstetrics and Gynaecology 2001; 23, 15-19.

25. Gunasekara PC, Wijesinghe PS, Goonewardene IMR. Caesarean section rate is rising. Ceylon Med J 2001; 46:147150.

26. Department of Census and Statistics Sri Lanka. Poverty indicators. Household income and expenditure survey. 2009-10 2011; $1(2): 2$

27. Phillips M. L. Treating post partum depression 2011. American Psychological Association 2011; 42(2):46. Available from URL: http://www. apa.org/monitor/2011/02/postpartum. aspx (Accessed on 20th July 2011) 


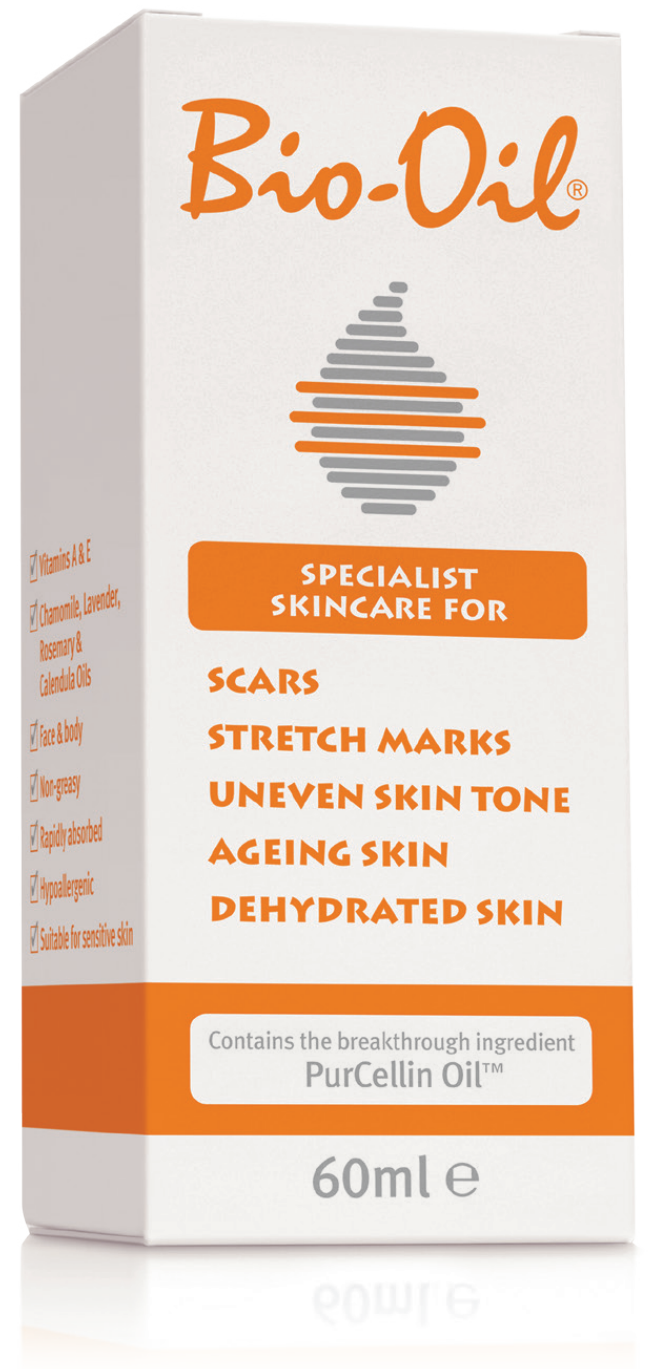

Bio-Oil@ is a skincare oil that helps improve the appearance of scars, stretch marks and uneven skin tone. It contains natural oils, vitamins and the breakthrough ingredient PurCellin Oil ${ }^{\mathrm{TM}}$. For comprehensive product information and results of clinical trials, please visit bio-oil.com. Bio-Oil is the No.1 selling scar and stretch mark product in 18 countries including UK. Price - Rs.941.00 (60ml).

Marketed in Sri Lanka by: Hemas Pharmaceuticals (Pvt) Ltd, 439,Galle Road, Colombo 3. 0114766666 / 0772962833 